Diversity and Distributions

The law of diminishing returns: woodland birds respond to native vegetation cover at multiple spatial scales and over time

Ross B. Cunningham ${ }^{1}$, David B. Lindenmayer ${ }^{1}$, Mason Crane ${ }^{1}$, Damian R. Michael ${ }^{1}$, Philip S. Barton ${ }^{1}$, Philip Gibbons ${ }^{1}$, Sachiko Okada ${ }^{1}$, Karen Ikin ${ }^{1}$, John A.R. Stein ${ }^{1}$

${ }^{1}$ Fenner School of Environment and Society, The Australian National University, Canberra, ACT 0200, Australia

ross.cunningham@anu.edu.au; david.lindenmayer@anu.edu.au; masoncrane@yahoo.com; damian.michael@anu.edu.au; philip.barton@anu.edu.au; philip.gibbons@anu.edu.au; okada.sachiko@gmail.com; karen.ikin@anu.edu.au; john.stein@anu.edu.au Corresponding author: David Lindenmayer, Fenner School of Environment and Society, The Australian National University, Canberra, ACT 0200, Australia. Email: david.lindenmayer@anu.edu.au. Tel: +612 61250654. Fax: +61 261250746.

Running title: Biodiversity, scale and vegetation cover

Article type: Biodiversity Research

Word Count: Abstract 300; main text 5657

Tables: 2

Figures: 4

References: 49 


\section{(A) Abstract}

(B) Aim: To quantify at multiple spatial scales: (1) spatial dependence in several measures of aggregate bird biodiversity, (2) the role of native vegetation cover in explaining variation in aggregate bird biodiversity, and (3) relationships between change over 8 years in bird diversity and changes in native vegetation.

(B) Location: South-eastern Australia.

(B) Methods: We gathered data on birds between 2002 and 2010 on 184 (2 ha) sites nested within 46 (1000 ha) farms nested within 23 (10,000 ha) landscapes. We statistically estimated spatial and temporal components of variation at the landscape, farm and site scale for several composite indices of bird diversity. Second, we modelled the relationships between aggregate bird biodiversity and $\log \%$ of native vegetation cover at each spatial scale and over time.

(B) Results: Variation in bird biodiversity at the landscape, farm, and site scale exhibited significant, intrinsic scale-specific effects. This dependence was largely accounted for by native vegetation cover with aggregate biodiversity increasing with increasing native vegetation cover at each spatial scale and over time. Every doubling of \% cover resulted in an increase of 3.1, 2.3, and 0.7 species per landscape, farm and site, respectively. Similar statistically significant positive relationship between proxy abundance and richness of species of conservation concern and \% cover of vegetation were also found. Species richness at the site scale also was related to vegetation cover in the surrounding landscape. Over the period of study, relationships between changes in bird biodiversity and changes in vegetation cover were not statistically significant.

(B) Main conclusions: We used 'diminishing returns' response curves to model relationships between measures of bird biodiversity and vegetation cover at all spatial scales. Absolute gains in biodiversity per unit increase in vegetation cover were greatest at relatively 
low amounts of vegetation cover. These results can help prioritise investment strategies like replanting native vegetation under agri-environment schemes.

(B) Keywords: Agri-environment schemes, bird occurrence, curves of diminishing marginal return, native vegetation cover, spatial dependence, spatial scale, vegetation restoration 


\section{(A) Introduction}

The concept of scale is central to ecology and refers to the spatial extent of ecological processes and the spatial interpretation of the data (Levin 1992; Chave 2013). For example, a given organism may exhibit a particular kind of response to the environment at a specific scale, but may respond differently at a larger or smaller scale (Allen \& Hoekstra 1992; Schneider 1994). We recognise a duality between the concepts of spatial scale and spatial dependence, where spatial dependence is the occurrence of similar values for a given entity (e.g. species richness) in close-by locations (Koenig 1998). This may arise because of similarity in environmental conditions, suitability of habitat, or because of population processes like meta-population dynamics among ensembles of nearby patches (Koenig 1998).

Despite widespread recognition of the importance of scale in ecology (Wiens 1989; Levin 1992), attempts to statistically quantify effects of spatial scale have often proved difficult (Meentemeyer \& Box 1987; Mackey \& Lindenmayer 2001; Collinge 2009; Chave 2013). This is a major issue from an applied perspective because there is no single 'right' or 'sufficient' scale for conservation management (Levin 1992). Indeed, a single conservation strategy adopted at a single spatial scale may meet only a limited number of management goals (Lindenmayer \& Hobbs 2007).

To provide novel insights into the effects of scale, here we present results from a nested, long-term study of relationships between bird biodiversity and vegetation cover at landscape, farm and site scales, and over time. Our investigation focussed on an agricultural region of south-eastern Australia (Fig. 1) and addressed three broad questions.

Question 1. Are there spatial scale and temporal effects on bird biodiversity? We analysed composite indices of bird diversity at the landscape, farm and site (i.e. within-farm) scales and estimated spatial and temporal components of variation at each of these scales. We then 
examined how much variation in our indices at small scales (site and farm) could be explained by larger (landscape) scales. At the outset of this investigation, we postulated the existence of scale effects in bird biodiversity for several reasons because of: (a) likely similar values in environmental conditions and habitat suitability in closely located areas, and (b) colonisation dynamics in closely located habitat patches (e.g. Cooper \& Walters 2002). In addition, key processes ranging from habitat selection to regional population dynamics manifest at different scales (Schneider 1994). For example, local ecological effects such as species-specific responses to habitat suitability may limit species richness at the individual site scale (Morrison et al., 2006). Conversely, movement of individuals between habitat patches across different sites may increase species richness at larger scales by adding particular taxa such as wide-ranging "resource-nomads" (sensu Recher 1999).

Question 2. How well does native vegetation cover explain variation in bird biodiversity at multiple spatial scales and over time? Although it is well known that there are strong relationships between bird biodiversity and vegetation cover, we were agnostic about the form of the relationships at the commencement of this investigation. Some authors have suggested efforts to increase vegetation cover will have greatest relative effect on gains in bird biodiversity in high cover areas (Parkes et al., 2003). Conversely, others argue the greatest gain in species richness will be in places with intermediate natural vegetation cover or low and structurally simple environments (Pardini et al., 2010; Kleijn et al., 2011).

Question 3. Does vegetation cover at larger spatial scales account for variation in bird biodiversity at smaller spatial scales? Examining relationships between species richness and other measures of bird biodiversity and vegetation cover at multiple scales is important for several reasons: (i) Most past work has focused at a single scale (typically the "landscape scale" as perceived by humans (e.g. $100 \mathrm{sq} \mathrm{km;} \mathrm{Radford} \mathrm{et} \mathrm{al.,} \mathrm{2005;} \mathrm{Maron} \mathrm{et} \mathrm{al.,} \mathrm{2012).} \mathrm{(ii)}$ Recent work by Tscharntke et al. (2012) has suggested there may be "spillover" effects with 
species richness at small scales influenced by vegetation cover at larger scales, but this premise has yet to be quantified. (iii) Most work on relationships between biodiversity and vegetation cover has focused on declining areas of habitat (e.g. Brooks 2002) but here we quantify responses to increasing levels of vegetation cover arising from natural regeneration and revegetation. We postulated there would be a strong positive relationship between bird biodiversity and the amount of vegetation cover, consistent with the findings of previous studies that have quantified the effects of the amount of habitat on species richness (Swift \& Hannon 2010; Maron et al., 2012; Tscharntke et al., 2012). We also anticipated there would be temporal increases in bird biodiversity at sites, on farms, and in landscapes because the amount of native vegetation cover in our study region has increased over the past 10-20 years through natural regeneration and revegetation programs.

New insights from this study have important implications for guiding major management activities such as restoration programs (Benayas et al., 2009). For example, the results provide guidance on the spatial scale at which efforts to increase the amount of native vegetation cover might yield the best gains for biodiversity (Tscharntke et al., 2012). Our findings also will provide an indication of whether efforts to restore vegetation cover are likely to have a direct effect on species gain within landscapes as distinct from localised effects observed across sites.

\section{(A) Materials and methods}

\section{(B) Study area}

Our study was conducted in a $150 \mathrm{~km}$ x $120 \mathrm{~km}$ area of the South-west Slopes of New South Wales, south-eastern Australia (Fig. 1). The predominant form of native vegetation was temperate eucalypt woodland (sensu Lindenmayer et al., 2010). The region was ideal for study because: (1) There was a wide range in spatial cover of native vegetation (from $3 \%$ to $35 \%$ ), and (2) native vegetation cover on some farms and in some landscapes has been 
increasing rapidly over the past two decades through revegetation (Lindenmayer et al., 2010) and natural regeneration (Geddes et al., 2011). These features can be seen as satellite-derived forest extent (Fig. 1).

\section{(B) Study design}

We gathered bird data from 2002 to 2010 on 184 sites (each of 2 ha). Four sites were nested within each of 46 farms (each of 1000 ha) that were wheat (Triticum spp) or canola (Brassica napus) cropping properties, or sheep (Ovis ovis) and cattle (Bos taurus) grazing enterprises. We then nested two farms within each of 23 landscapes (defined as a relatively homogenous circular area covering 10,000 ha) (Fig. 1). The overall size of our investigation was large and characterised by many replicates of landscapes $(\mathrm{N}=23)$, farms $(\mathrm{N}=46)$ and sites $(\mathrm{N}=184)$. This, in many ways, statistically obviates the need for high-intensity sampling throughout individual farm and landscape units. Cunningham et al. (2007) provides further details of the experimental design.

\section{(B) Bird surveys}

Our study region supports more than 170 bird species (see Table S1 in Supporting Information). Over half of these species are woodland dependent (Silcocks et al., 2005). These include more than 20 species of conservation concern (sensu Reid 1999; MontagueDrake et al., 2009) (see Table S1). The bird community in the study region includes a range of native "generalist" species that occur in heavily cleared paddocks and cultivated areas (e.g. the Brown Songlark, Cincloramphus cruralis). Only four species are exotic, of which the House Sparrow (Passer domesticus) and Common Starling (Sturnus vulgaris) have been declining significantly over the past decade (Lindenmayer \& Cunningham 2011).

We surveyed birds on the 184 sites in spring 2002, 2004, 2005, 2007, 2009, and 2010. Our bird counting protocols entailed repeated 5 minute point interval counts at the $0 \mathrm{~m}, 100$ $\mathrm{m}$ and $200 \mathrm{~m}$ points along the permanent transect at each site. In each survey year, all sites 
were surveyed by two different observers on different days. We completed counts between sunrise and mid-morning using protocols identical to those in our other long-term major studies in temperate eucalypt woodlands in south-eastern Australia (Montague-Drake et al., 2009).

\section{(B) Response variables}

Combining information across species can provide useful measures of aggregate biodiversity to assess scale aspects and relationships between diversity and vegetation cover. Composite indices analysed and presented were the overall number of species (R), the number of species of conservation concern $(\mathrm{C})$, and a proxy measure of relative abundance (A). Ecologists have dedicated considerable effort in analysing and predict richness and relative abundance (Rosenzweig 1995; Gaston \& Spicer 2004) and land managers use richness frequently in developing strategies for managing natural resources, including biodiversity.

Our species richness measures, $\mathrm{R}$ and $\mathrm{C}$, were the total number of species and the number of species of conservation concern, recorded at a site, farm or in a landscape, respectively. Our measure of relative abundance (A) (Cunningham and Olsen 2008) was the mean of odds ratios for 49 species with mean reporting rates $>5 \%$ and $<95 \%$. At the site level, we excluded data on several species because of low mean reporting rates, giving 35

species. Thus $\mathrm{A}=\frac{1}{49} \sum_{1}^{49} \log 100 \frac{p}{1-p}$ where interpolated reporting rate at 2002 and 2010. Low values for the index of relative abundance corresponded to low abundance and high values corresponded to high average abundance.

\section{(B) Vegetation cover as a potential explanatory variable}

We considered four measures of vegetation cover: the total (\%) amount of woody vegetation cover, the number of native vegetation patches, the average patch area (ha), and the standard deviation of patch area. We calculated each of these measures at the site (within 
500 metres of the centre of a site), farm (1000 ha) and landscape (10,000 ha) scales using grids of annual Forest Extent and change between 2002 and 2010 derived from satellite imagery (Furby 2002). Grid resolution was $25 \mathrm{~m}$ x $25 \mathrm{~m}$ and vegetation cover was allocated to grid cells where the minimum canopy cover was $20 \%$ over a minimum area of 0.2 ha with potential height at least $2 \mathrm{~m}$.

\section{(A) Statistical analyses}

Our objective in the first part of the analysis was to obtain a 'best' estimate of site, farm and landscape scale bird species richness (R and C) and our index of bird abundance (A) at two time points -2002 and 2010. The second part of our analysis was to develop models of relationships between our measures of aggregate bird biodiversity and native vegetation cover at three spatial scales as well as over time. We describe below the analysis for landscape-scale species richness (R). We then repeated this process with farms and sites replacing landscapes, separately, and with the other biodiversity measures, $\mathrm{C}$ and $\mathrm{A}$, replacing species richness.

\section{(B) 1. Interpolation of estimates of landscape bird richness in 2002 and 2010}

Considering all survey years simultaneously, we fitted a multiple regression model with species richness as the response variable with the fixed effects being the terms 'Landscape', 'Year' (as a linear effect) and the interaction term Landscape $\times$ Year. This model facilitated prediction of 'smoothed' species richness values at each landscape for each year, together with estimates of the variance of the predicted values. We completed a similar process for relative abundance, where the predicted odds ratios for each of the 49 species were obtained for the years 2002 and 2010 by linear logistic regression, where the response variable was presence/absence of a given bird species and the fixed effects were Landscape, Year and Landscape $\times$ Year interaction terms.

\section{(B) 2. Modelling the relationship between bird biodiversity and vegetation cover}


For simplicity, we consider a statistical model for landscape-scale bird species richness. Our response variable species richness then varied at three levels: between-landscape, between- year, and between-year within-landscape. The candidate explanatory variables representing vegetation cover (primarily here the log of $\%$ vegetation covers) also varied at these levels.

We recognised in our statistical analysis that repeat observations of bird species richness within a landscape might be more homogeneous than observations between landscapes. That is, we would expect some within-landscape correlation between the repeat species richness values. This suggested the factor 'Landscape' should therefore be treated as a random effect in our model. For similar reasons 'Year' was included as a random effect.

If we regard Landscape $(l)$ and Year $(y)$ as random effects and vegetation cover as a fixed effect, we have:

$$
Y_{i j}=\mu+l_{i}+y_{j}+\beta X_{i j}+\varepsilon_{i j}
$$

$\mu=$ grand mean; $\beta=$ the regression coefficient for the explanatory variable $X_{i j}$, the $\log$ vegetation cover. Assume $l_{i}, i=1, \cdots, 23$, independent $N\left(0, \sigma_{l}^{2}\right), y_{j}, j=1,2$ independent $N\left(0, \sigma_{y}^{2}\right)$, and $\varepsilon_{i j}$ independent $N\left(0, \sigma_{\varepsilon}^{2}\right)$, where $\sigma_{l}^{2}, \sigma_{y}^{2}, \sigma_{\varepsilon}^{2}$ are known as variance components. $Y_{i j}$ denotes bird richness on the $i$ th landscape in the $j$ th year.

The above model fits within the general framework of general linear mixed models (Galwey 2006). Restricted maximum likelihood was used to estimate variance components and weighted least squares for estimating fixed effects. We assessed statistical significance of effects by calculating adjusted Wald statistics (Kenward \& Rogers 1997). We based extrinsic weights on the standard errors of the predicted values of species richness in 2002 and 2010 obtained from the previous analysis. We used general model checking procedures to identify aberrant data and to check model assumptions. 
The variance of an observation of richness in a landscape in one year was:

$$
\operatorname{Var}\left(Y_{i j k}\right)=\sigma_{l}^{2}+\sigma_{y}^{2}+\sigma_{e}^{2}
$$

A measure of dependence between repeat observations in the same landscape was the within-landscape correlation viz:

$$
\rho=\frac{\sigma_{l}^{2}}{\sigma_{l}^{2}+\sigma_{y}^{2}+\sigma_{e}}
$$

For our study, spatial variance components provided a measure of variation of observations at a given scale, and therefore provided statistics for calculating spatial dependence (and hence scale effects).

Our models for farm and site bird species richness included additional, larger spatial random terms and hence components of variance (i.e. landscape for the farm-level analysis and farm and landscape for the site-level analysis; see tables in Supporting Information). Therefore, models for farm and site bird species richness were mathematically more complicated than those for landscape scale analysis outlined above.

\section{(A) Results}

\section{(B) General findings}

We recorded 171 species of birds in our study, including 21 species of conservation concern (Table S1). We then considered four measures of vegetation cover and their relationships with overall bird species richness and the richness of bird species of conservation concern. We found strong effects for one of these measures $-\log \%$ of native vegetation cover - with only very limited additional information from analysing the other three (i.e. number of patches, average patch area, the standard deviation of patch area). Therefore, we present findings only for log \% vegetation cover.

Between 2002 and 2010, the geometric mean of \% vegetation cover increased from 3.6 to 4.2 at the landscape scale, 3.1 to 3.8 at the farm scale, and 1.9 to 2.8 at the site scale. 
During this time, species richness (R) increased by 3.2 species (from 38.5 species) at the landscape scale $(\mathrm{P}=0.07), 2.4$ species (from 27.5 species) at the farm scale $(\mathrm{P}=0.008)$, and 0.5 species (from 13 species) at the site scale $(\mathrm{P}=0.15)$. Richness of species of conservation concern (C) increased by 0.13 (from 3.1), 0.04 (from 2.1) and 0.2 (from 1.2) for landscapes, farms and sites respectively. The abundance index (A) changed from 0.35 , from 1.2 (this is equivalent to an increase in median reporting rate from 4.5 to 5.2), 0.03 (from 0.13 ) and -0.2 (from -2.6), for landscapes, farms and sites respectively.

In the remainder of the Results section, we summarise our findings, firstly as a decomposition of total variation in bird biodiversity $(\mathrm{R}, \mathrm{C}$ and $\mathrm{A})$ into the relevant random components (ANOVA) and secondly, the amount of variation in bird biodiversity explained by $\log \%$ of native vegetation cover for each component.

\section{(B) Response 1 (a): Species richness per landscape}

At the landscape scale, $44 \%$ of the variance of a single observation of species richness was attributable to landscape scale variation and $4 \%$ was attributable to year to year variation (Table 1). Furthermore, $83 \%$ of the landscape component of variance and $55 \%$ of the year component of variance could be explained by $\log \%$ vegetation cover (Table 1 ). The intralandscape correlation between landscape richness values was reduced from 0.44 to 0.12 , confirming that much of the heterogeneity in landscape species richness could be explained by $\log \%$ vegetation cover.

We summarise the between-landscape and within-landscape relationships between species richness and vegetation cover in Table 2 and Fig. 2. The between-landscape slope $(4.5, \mathrm{se}=0.96)$ represents the difference in the mean species richness between two landscapes

which differ by 1 unit in $\log \%$ native vegetation cover. The within-landscape slope $(-0.7$, $\mathrm{se}=6.7$ ) represents, for a given landscape, the increase in the change in species richness per unit change in difference in log \% vegetation cover between 2002 and 2010 . This is the direct 
effect on species richness of increasing $\log \%$ native vegetation cover by one unit within a given landscape. This is clearly not statistically significant $(\mathrm{p}=0.4)$.

The magnitude of additive gains in species richness reduced as the absolute value of native vegetation cover increased in a linear way (Fig. 2B). Hence, the profile of the response was one of 'diminishing marginal returns'. Converting our results to log base 2, we found that a doubling of native vegetation cover in the 8 year period resulted in an increase of 3.1 (95\% CI: 1.7, 4.5) bird species per landscape (Fig. 2B), and this does not depend on the \% cover of vegetation in the year 2002 .

\section{(B) Response 1 (b): Number of bird species of conservation concern per landscape}

We found that $38 \%$ of the variance of an individual observation of the richness of birds of conservation concern per landscape was attributable to landscape scale variation and $0 \%$ was attributable to year to year variation (Table 1). In addition, $56 \%$ of the landscape component of variance could be explained by native woody vegetation cover (Table 1).

Doubling of $\%$ native vegetation cover resulted in an increase of 0.32 (95\% CI: 0.10 , 0.54) species of conservation concern per landscape (Table 2; Fig. 2C); the mean number of species of conservation concern per landscape was 3.1 species.

\section{(B) Response 1 (c): Index of aggregate abundance per landscape}

We found that $47 \%$ of the variance of an individual observation of aggregate abundance was attributable to landscape scale variation and $1.3 \%$ was attributable to year to year variation (Table 1). In addition, $77 \%$ of the landscape component of variance could be explained by native woody vegetation cover (Table 1).

Doubling of $\%$ native vegetation cover resulted in an increase of 0.40 (95\% CI: 0.13 , 0.66) in the abundance index per landscape (Table 2; Fig. 2C); the mean per landscape was 1.4 which corresponds to a median reporting rate of $5 \%$.

\section{(B) Response 2: Species richness per farm}


We found that $49 \%$ of the variance in an individual observation of species richness per farm could be attributed to variance between farms, 13\% between landscapes, and 3.9\% due to overall differences between 2002 and 2010 (Table S2). The landscape by year variance components represents variation in random temporal slopes between landscapes (i.e. the tendency for temporal changes in species richness at a farm scale to be non-constant between landscapes). This accounted for $9.5 \%$ of the variance of an observation (i.e. species richness per farm) (Table S2).

Vegetation cover reduced within-farm correlation in species richness from 0.63 to 0.48 . Farm scale and the landscape scale vegetation cover, considered simultaneously, accounted for $71 \%$ of the landscape variance, $75 \%$ of the year variance, and $34 \%$ of the between-farm (within a landscape) variance. Only $2 \%$ of the variance in the change in species richness between 2002 and 2010 at the landscape scale was accounted for by farm and landscape \% vegetation cover (Table S2). These findings suggest that factors in addition to the amount of vegetation cover are operating at the landscape scale to affect temporal change in farm-scale species richness.

There was no evidence of strong effects on changes in species richness resulting from the temporal change in native vegetation cover on a farm (Fig. 3A). The between farm regression relationship (Table S3) indicated that every doubling of native vegetation cover at the farm scale resulted in an increase of $2.3(95 \%$ CI: $1.3,3.3)$ species of birds per farm (Fig. 3B).

The significant overall landscape component of variance indicated that farms within landscapes were more similar in values for species richness than farms in different landscapes.

(B) Response 2 (b): Number of bird species of conservation concern per farm 
The mean number of species of conservation concern at the farm scale 2.1 and was significantly $(\mathrm{p}=0.008)$ related to the $\log \%$ vegetation cover in a farm; for every doubling of native vegetation cover at the farm resulted in an increase of 0.20 (95\% CI: $0.06,0.34)$ species of birds of conservation concern per farm (Fig. 3C).

\section{(B) Response 2 (c): Index of aggregate abundance per farm}

As with species richness, the between farm component of variance was the dominant component and much of this could be accounted for by vegetation cover at the farm scale. Doubling of $\%$ native vegetation cover resulted in an increase of $0.35(95 \%$ CI: $0.12,0.57)$ in the abundance index per farm (Fig. 2C); the mean per farm was 0.15 which corresponds to a median reporting rate of $1.4 \%$.

\section{(B) Response 3: Species richness per site}

We found that $36 \%$ of the variance of an individual observation of species richness per site could be attributed to variance between sites, $6 \%$ between farms, $8 \%$ between landscapes, $11 \%$ to random temporal slopes between landscapes, and $0 \%$ due to overall differences between 2002 and 2010 (Table S4). Vegetation cover at the site level accounted for less of the inherent site-to-site variation, reducing the intra-site correlation from 0.51 to 0.45 .

Decomposition of the overall relationship between species richness and $\log \%$ native vegetation cover at the site scale into between-site and within-site regression is shown in Fig. 4A. At the site scale, the slope of the temporal regression relationship for the change in species richness between 2002 and 2010 versus change in log \% vegetation cover over the corresponding period was small (Figure 5A). Temporal changes in site-scale species richness were significantly related to changes in the amount of vegetation cover at the landscape scale but not at the farm or site scales (Table S4).

Every doubling of the cover of native woody vegetation resulted in an increase of 0.65 (95\% CI: 0.35, 0.94) bird species per site (Fig. 4B; Table S5). 


\section{(B) Response 3 (b): Number of bird species of conservation concern per site}

The mean number of species of conservation concern at the site scale was 1.3 and was significantly $(\mathrm{p}<0.001)$ related to the $\log \%$ vegetation cover in a site; for every doubling of native vegetation cover at the site resulted in an increase of 0.26 (95\% CI: $0.17,0.34)$ species of birds of conservation concern per site (Fig 4C).

\section{(B) Response 3 (c): Index of aggregate abundance per site}

The results for the index of aggregate bird abundance were similar to those for overall richness, although the evidence for explaining abundance by vegetation cover measured at the landscape scale was weaker and not statistically significant. Every doubling of native vegetation cover at site resulted in an increase of 0.19 (95\% CI: $0.02,0.37)$ in our abundance index (Fig 4D). The relationship between change in the index of abundance and temporal change in vegetation cover was not statistically significant.

\section{(A) Discussion}

Levin (1992, p. 1943) argued the "problem of pattern and scale is the central problem in ecology, unifying population biology and ecosystem science, and marrying basic and applied ecology". We have addressed three key spatial scale-related questions by using repeated measures data from a spatially nested study design to quantify: (1) scale effects for several measures of aggregate biodiversity, and, (2) relationships between biodiversity measures and vegetation cover at the site, farm and landscape scales and over time (2002 and 2010). Our analyses revealed the following key findings:

- Significant patterns of spatial dependence at the landscape, farm and site scales.

- High explanatory value of log \% vegetation cover in explaining observed patterns of spatial dependence in overall species richness, on our index of abundance, and on species richness of birds of conservation concern at all spatial scales. 
- Significant positive relationships between bird biodiversity on a site and the $\log \%$ native vegetation cover at a site, and also the $\log \%$ vegetation cover at the landscape scale.

- Temporal changes in landscape-scale vegetation cover had value in explaining changes in bird biodiversity at site scales.

We further discuss these and other key findings in the remainder of this paper and then conclude with key implications of our work for vegetation restoration and bird conservation.

\section{(B) 1. Patterns of spatial dependence}

At all three spatial scales, observations between repeat measures over time at a given site, farm or landscape were more alike than observations between scales. The amount of native vegetation cover accounted for much of this observed dependence in species richness at all spatial scales (see the following section). We also found some evidence of spatial dependence between sites within farms and farms within landscapes. Similarities in bird species richness on sites within the same farm might arise due to farm-level management practices such as levels of fertilizer or pesticide application (Barrett 2000; Gabriel et al., 2010). Further spatial dependence between farms within the same landscape might arise because of levels of productivity (Maron et al., 2012), or cross-farm management (e.g. a hiatus in poison-baiting programs that result in increased numbers of wide-ranging exotic predators such as the introduced Red Fox (Vulpes vulpes) (Shapira et al., 2008)). Other processes like meta-population dynamics and source-sink dynamics that can influence extinction-colonisation phenomena in vegetation patches (Hanski 1999) also might influence patterns of spatial dependence (Koenig 1998). However, detailed data on the demography of populations of species within individual patches (e.g. see Zanette 2000) are required to quantify whether source-sink dynamics are operating in the ecosystems that we investigated. 
We have not gathered such data; nor to the best of our knowledge have others studying the avifauna of temperate eucalypt woodlands of south-eastern Australia.

The number of bird species on a site was related to the amount of native vegetation cover at the landscape scale (after having accounted for vegetation cover at the site scale). Several factors may account for these effects, including: (1) inter-patch movements, patch colonisation and rescue-effects (Hanski 1999), (2) regional populations of species (Askins \& Philbrick 1987) that in turn provide a source of colonists, which then invade patches from surrounding areas, and (3) boundary conditions and edge effects (Lindenmayer et al., 2009).

\section{(B) 2. Bird biodiversity relationships with vegetation cover}

We found that the 'best' representation of relationships between overall species richness, the richness of birds of conservation concern, our index of abundance, and vegetation cover at all spatial scales was one of 'diminishing marginal returns' (Figs. 2B-D, 3B-D, 4B-D). That is, relationships in which the absolute gains in species richness per unit increase in vegetation cover were greatest at relatively low amounts of vegetation cover (e.g. $5-10 \%)$. The increasing richness of bird species of conservation concern with increasing vegetation cover, including at low levels of vegetation cover (see Fig. 2C, 3C, 4C) suggests our results were not simply due to increases in the number of generalist or exotic species.

Given the level of inherent variability in the relationship between species richness and the amount of native vegetation cover, no other more complex relationship (such as other curvilinear relationships or a 'broken-stick' [threshold] model) was preferred over the simple statistical model $\mathrm{Y}=\mathrm{a}+\mathrm{b} \operatorname{logX}$. Our analyses do not exclude the possibility that more complicated models might be appropriate for bird species richness-vegetation cover relationships, but it was not possible to find unequivocal empirical support for so called “threshold" models (i.e. models exhibiting a discrete breakpoint) (cf. Radford et al., 2005). 
Also we do not exclude the possibility that individual species that depend on more extensive intact habitat may show different patterns.

Our findings were consistent with the results of other studies that have demonstrated links between the number of species present in a given area and the amount of 'habitat' in that area (e.g. via the species area curve; Rosenzweig 1995; Gaston \& Spicer 2004). Our 'diminishing returns' model for the relationship between bird species richness and the $\%$ cover of woody native vegetation is consistent with simple equations used to describe the well-studied species-area curve (Arrhenius 1921; Preston 1962; Rosenzweig 1995). Notably, species-area equations have been used to predict rates of species extinction where $\%$ habitat cover has been used as a substitute for area - as usually defined as area of contiguous native vegetation (e.g. an island or a patch "intact" forest surrounded by a cleared non-forest matrix) (Brooks 2002).

\section{(B) Does vegetation cover at larger spatial scales influence bird biodiversity at}

\section{smaller spatial scales?}

An unexpected result was that the temporal change in the amount of vegetation cover between 2002 and 2010 at the landscape scale had a significant effect on changes in species richness at the site level. That is, changes in species richness on a site between 2002 and 2010 were positively related to temporal changes in vegetation cover at the landscape scale (Table S5). This is an important finding as most past work on relationships between biodiversity and vegetation cover has focused on declining areas of habitat (e.g. Brooks 2002) but here we have quantified species richness and other responses to temporal increases in vegetation cover arising from natural regeneration and revegetation. We have not examined the potential for time lag effects on species loss (e.g. extinction debts [sensu Tilman et al., 1994]; Lindenmayer and Fischer 2006). Such lag effects may exist in the temperate eucalypt woodlands that we studied, but our data lack the level of precision needed to detect them (if 
they occur). However, we do note that the richness of species of conservation concern (which may be those taxa most prone to lag effects) exhibited significant positive relationships with the amount of native vegetation cover.

Several factors may explain why changes in landscape-scale vegetation cover influence farm and site-level outcomes. These include: (1) landscape context effects in which a determinant of the biota in patches is the amount and condition of the vegetation surrounding those patches (Lindenmayer et al., 2008), (2) regional species pool effects (Askins \& Philbrick 1987) in which organism occurrence within individual patches is influenced by overall population and assemblage composition at a regional scale, and (3) dispersal and associated processes like meta-population dynamics (Hanski 1999) that, for some species of birds, may operate at landscape scales but, in turn, influence occurrence (and patterns of spatial dependence) at smaller farm and site scales.

\section{(B) 4ractical implications}

An important conservation question in agricultural areas such as those targeted under agri-environment schemes is: 'Will the greatest biodiversity gains from investments in restoration occur at high, intermediate or low levels of remnant vegetation cover'? Our analyses revealed the 'best model' was a curve of 'diminishing returns'. Hence, the highest relative gains in biodiversity will be at lower levels of native vegetation cover (e.g. when increasing vegetation cover from 5-10\%). Doubling the amount of native vegetation is also, from a practical perspective (given other land use demands such as cropping and domestic livestock grazing), easier to achieve at lower levels of vegetation cover than at higher levels (e.g. from $15-30 \%)$.

A potential issue with a diminishing marginal returns curve for species richness could be that bird species of conservation concern might be recruited only at high levels of vegetation cover in a site, farm or landscape. However, our analyses clearly showed that the 
response curves for the richness of species of conservation concern were similar to those for overall species richness. Indeed, we showed that absolute gains in richness for birds of conservation concern per unit increase in vegetation cover were greatest at relatively low amounts of vegetation cover (Figs. 2C, 3C and 5C). This finding is congruent with other investigations in our study region indicating species of conservation concern often occupy replanted areas and stands of natural regrowth (Lindenmayer et al., 2012) - which are typically the most prevalent form of vegetation cover in extensively cleared farms and landscapes (Cunningham et al., 2007). We do, however, note that some species of conservation concern may colonise a site or a farm only if key nesting and/or foraging resources are available, and this may be associated not only with the amount of vegetation cover but also the type and quality of that cover.

New insights from this study do not discount the conservation value of improving the condition of existing areas of remnant native vegetation (Lindenmayer et al., 2012), nor do they undermine the importance of protecting high quality stands of temperate eucalypt woodland (Montague-Drake et al., 2009). Rather, we reiterate that if a management objective is to increase overall bird species richness or the richness of bird species of conservation concern, then investment strategies aimed at achieving this would be best targeted at landscapes with comparatively low vegetation cover levels.

Although some parts of our study region support relatively limited vegetation cover (e.g. $<4 \%$ of the landscape), we found no direct evidence of areas being so heavily cleared they were beyond remediation (e.g. "triage landscapes"; Hobbs et al., 2003). Rather, the diminishing returns response curves suggest that revegetation programs, even within areas of low native vegetation cover (e.g. 3-5\%), can have significant positive benefits for increasing bird species richness. 
We found that the temporal change in species richness at the site scale was related to the change in vegetation cover at the landscape scale as well as at the site scale. Restoration programs in a given landscape will therefore result not only in increased bird species richness in that landscape, but also on sites and farms within that landscape. In addition, landscapescale restoration may result in increased species richness on farms and sites where no restoration has taken place. A significant implication is that species richness benefits accrue from multiple land managers working collectively at the landscape level. This, in turn, highlights the benefits for biodiversity conservation that might arise from co-ordinated revegetation programs at large spatial scales.

\section{(A) Acknowledgements}

This study was supported through grants from the Murray Catchment Management Authority, the Australian Research Council and the Caring for Our Country Program. We thank Emmo Willinck and David Lesslie for their support of this project. Claire Shepherd assisted with many aspects of manuscript preparation.

\section{(A) References}

Allen, T.F.H. \& Hoekstra, T.W. (1992) Toward a Unified Ecology. Columbia University Press, New York.

Arrhenius, O. (1921) Species and area. Journal of Ecology, 9, 95-99.

Askins, R.A. \& Philbrick, M.J. (1987) Effects of changes in regional forest abundance on the decline and recovery of a forest bird community. Wilson Bulletin, 99, 7-21.

Barrett, G. (2000) Birds on farms: ecological management for agricultural sustainability. Wingspan, 10, 1-16.

Benayas, J.M.R., Newton, A.C., Diaz, A. \& Bullock, J.M. (2009) Enhancement of biodiversity and ecosystem services by ecological restoration: a meta-analysis. Science, $\mathbf{3 2 5}$, $1112-1124$. 
Brooks, T.M. (2002) Habitat loss and extinction in the hotspots of biodiversity. Biological Conservation, 16, 909-923.

Chave, J. (2013) The problem of pattern and scale in ecology: what have we learned in 20 years? Ecology Letters, 16, 4-16.

Collinge, S.K. (2009) Ecology of Fragmented Landscapes. The John Hopkins University Press, Baltimore.

Cooper, C.B. \& Walters, J.R. (2002) Experimental evidence of disrupted dispersal causing decline of an Australian passerine in fragmented habitat. Conservation Biology, 16, 471-478. Cunningham, R.B., Lindenmayer, D.B., Crane, M., Michael, D. \& MacGregor, C. (2007) Reptile and arboreal marsupial response to replanted vegetation in agricultural landscapes. Ecological Applications, 17, 609-619.

Cunningham, R. \& Olsen, P. (2009) A statistical methodology for tracking long-term change in reporting rates of birds from volunteer-collected presence-absence data. Biodiversity and Conservation, 18, 1305-1327.

Furby, S. (2002) Land Cover Change: Specifications for Remote Sensing Analysis. National Carbon Accounting System (NCAS) Technical Report No. 9). Australian Greenhouse Office, Canberra.

Gabriel, D., Sait, S.M., Hodgson, J.A., Schmutz, U., Kunin, W.E. \& Benton, T.G. (2010) Scale matters: the impact of organic farming on biodiversity at different spatial scales. Ecology Letters, 13, 858-869.

Galwey, N.W. (2006) Introduction to mixed modelling: beyond regression and analysis of variance. John Wiley, London.

Gaston, K.J. \& Spicer, J.I. (2004) Biodiversity: An introduction. Blackwell Publishing, Oxford. 
Geddes, L.S., Lunt, I.D., Smallbone, L. \& Morgan, J.W . (2011) Old field colonization by native trees and shrubs following land use change: could this be Victoria's largest example of landscape recovery? Ecological Management \& Restoration, 12, 31-36.

Hanski, I. (1999) Metapopulation Ecology. Oxford University Press, Oxford.

Hobbs, R.J., Cramer, V.A. \& Kristjanson, L.J. (2003) What happens if we cannot fix it? Triage, palliative care and setting priorities in salinising landscapes. Australian Journal of Botany, 51, 647-653.

Hurlbert, S.H. (1972) The nonconcept of species diversity: a critique and alternative parameters. Ecology, 52, 577-586.

Kenward, M.G. \& Rogers, J.H. (1997) Small sample inference for fixed effects from restricted maximum likelihood. Biometrics, 53, 983-997.

Kleijn, D., Rundlof, M., Scheper, J., Smith, H.G. \& Tscharntke, T. (2011) Does conservation on farmland contribute to halting biodiversity decline? Trends in Ecology and Evolution, 26, $474-481$.

Koenig, W.D. (1998) Spatial autocorrelation in California land birds. Conservation Biology, $12,612-620$.

Levin, S.A. (1992) The problem of scale and pattern in ecology: The Robert H. Macarthur Award lecture. Ecology, 73, 1943-1967.

Lindenmayer, D.B., Bennett, A.F. \& Hobbs, R.J. (Eds) (2010) Temperate Woodland Conservation and Management. CSIRO Publishing, Melbourne.

Lindenmayer, D.B. \& Cunningham, R.B. (2011) Longitudinal patterns in bird reporting rates in a threatened ecosystem: Is change regionally consistent? Biological Conservation, 144, $430-440$.

Lindenmayer, D.B., Cunningham, R.B., MacGregor, C., Crane, M., Michael, D., Fischer, J., Montague-Drake, R., Felton, A. \& Manning, A. (2008) Temporal changes in vertebrates 
during landscape transformation: a large-scale "natural experiment". Ecological Monographs, 78, 567-590.

Lindenmayer, D.B. \& Hobbs, R. (Eds) (2007) Managing and Designing Landscapes for Conservation: Moving from Perspectives to Principles. Blackwell Publishing, Oxford. Lindenmayer, D.B., Knight, E.J., Crane, M.J., Montague-Drake, R., Michael, D.R. \& MacGregor, C.I. (2010) What makes an effective restoration planting for woodland birds? Biological Conservation, 143, 289-301.

Lindenmayer, D.B., Northrop-Mackie, A.R., Montague-Drake, R., Michael, D., Crane, M., Okada, S., MacGregor, C. \& Gibbons, P. (2012) Not all kinds of regrowth are created equal. Regrowth type influences bird assemblages in threatened Australian woodland ecosystems. PLOS One, 7, e34527.

Lindenmayer, D.B., Wood, J., Montague-Drake, R., Michael, D., Crane, M., Okada, S., MacGregor, C. \& Gibbons, P. (2012) Is biodiversity management effective? Cross-sectional relationships between management, bird response and vegetation attributes in an Australian agri-environment scheme. Biological Conservation, 152, 62-73.

Lindenmayer, D.B., Wood, J.T., Cunningham, R.B., Crane, M., MacGregor, C., Michael, D. \& Montague-Drake, R. (2009) Experimental evidence of the effects of a changed matrix on conserving biodiversity within patches of native forest in an industrial plantation landscape. Landscape Ecology, 24, 1091-1103.

Mackey, B.G. \& Lindenmayer, D.B. (2001) Towards a hierarchical framework for modelling the spatial distribution of animals. Journal of Biogeography, 28, 1147-1166.

Maron, M., Bowen, M., Fuller, R.A., Smith, G.C., Eyre, T.J., Mathieson, M., Watson, J.E. \& McAlpine, C.A. (2012) Spurious thresholds in the relationship between species richness and vegetation cover. Global Ecology and Biogeography, 21, 682-692. 
Meentemeyer, V. \& Box, E.O. (1987) Scale effects in landscape studies. Landscape Heterogeneity and Disturbance. (ed. by M.G. Turner), pp. 15-34. Springer-Verlag, New York.

Montague-Drake, R.M., Lindenmayer, D.B. \& Cunningham, R.B. (2009) Factors affecting site occupancy by woodland bird species of conservation concern. Biological Conservation, 142, 2896-2903.

Morrison, M.L., Marcot, B.G. \& Mannan, R.W. (2006) Wildlife-Habitat Relationships. Concepts and Applications. Island Press, Washington, D.C.

Pardini, R., de Arruda Bueno, A., Gardner, T.A., Prado, P.I. \& Metzger, J.P. (2010) Beyond the fragmentation threshold hypothesis: Regime shifts in biodiversity across fragmented landscapes. PLOS One, 5, e1 3666.

Parkes, D., Newell, G. \& Cheal, D. (2003) Assessing the quality of native vegetation: The 'habitat hectares' approach. Ecological Management \& Restoration, 4, S29-S38.

Preston, F.W. (1962) The canonical distribution of commonness and rarity. Ecology, 43, 185$215,410-432$.

Radford, J.Q., Bennett, A.F. \& Cheers, G.J. (2005) Landscape-level thresholds of habitat cover for woodland-dependent birds. Biological Conservation, 124, 317-337.

Recher, H.F. (1999) The state of Australia's avifauna: a personal opinion and prediction for the new millennium. Australian Zoologist, 31, 11-29.

Reid, J. (1999) Threatened and declining birds in the New South Wales sheep-wheat belt. I. Diagnosis, characteristics and management. Unpublished report to NSW National Parks and Wildlife Service, CSIRO Wildlife and Ecology, Canberra.

Rosenzweig, M.L. (1995) Species Diversity in Space and Time. Cambridge University Press, Cambridge. 
Schneider, D.C. (1994) Quantitative Ecology. Temporal and Spatial Scaling. Academic Press. San Diego, California.

Shapira, I., Sultan, H. \& Shanas, U. (2008) Agricultural farming alters predator-prey interactions in nearby habitats. Animal Conservation, 11, 1-8.

Silcocks, A., Tzaros, C., Weston, M. \& Olsen, P. (2005) An interim guild classification for Australian woodland and grassland birds. Birds Australia Supplementary Report to State of the Environment Report 2006.

Swift, T.L. \& Hannon, S.J. (2010) Critical thresholds associated with habitat loss: a review of the concepts, evidence and applications. Biological Reviews, 85, 35-53.

Tscharntke, T., Tylianakis, J.M., Rand, T.A., Didham, R.K., Fahrig, L., Batary, P., Bengtsson, J., Clough, Y., Crist, T.O., Dormann, C.F., Ewers, R.M., Frund, J., R.D., H., Holzschuh, A., Klein, A.M., Kleijn, D., Kremen, C., Landis, D.A., Laurance, W., Lindenmayer, D.B., Scherber, C., Sodhi, N., Steffan-Dewenter, I., Thies, C., van der Putten, W. \& Westphal, C. (2012) Landscape moderation of biodiversity patterns and processes eight hypotheses. Biological Reviews, 87, 661-685.

Wiens, J.A. (1989) Spatial scaling in ecology. Functional Ecology, 3, 385-397. 


\section{BIOSKETCH}

(A) General statement of focus of research team: This publication is generated from long-term empirical studies by the Australian temperate woodlands research group at the Fenner School of Environment and Society. For the past 14 years, the research group has focused on approaches which attempt to integrate the conservation of biodiversity with agricultural production in Australian woodland landscapes. The research team includes expert statistical scientists, field-based ecologists dedicated to gathering high quality field data, and ecologists with particular expertise in theory.

(A) Statement of author roles: $\mathrm{RC}$ and DBL designed the study; RC completed the detailed statistical analysis; DBL, MC, DRM, SO gathered the field data; JARS and MC generated the spatial data on vegetation cover at different spatial scales; RC and DBL wrote the paper with significant conceptual and editorial input from PSB, KI and PG. 


\section{(A) Supporting Information}

Additional Supporting Information may be found in the online version of this article:

Table S1. Complete list of observed bird species recorded in surveys conducted between 2002 and 2010 in the South West Slopes of New South Wales, south-eastern Australia

Table S2. Variance components for biodiversity measures at the farm scale

Table S3. Parameters and associated statistics for relationships between measures of biodiversity on a farm and $\log \%$ native vegetation cover at the farm scale

Table S4. Variance components for richness and abundance at the site scale for all scales in the hierarchical design (i.e. the site, farm and landscape scales and over time)

Table S5. Parameters and associated statistics for relationships between richness and abundance and $\log \%$ native vegetation cover at the site and landscape scales 
Table 1. Variance components and the amount of variation explained by $\log \%$ of native vegetation cover for three measures of aggregate biodiversity at the landscape scale: overall number of species (R), the number of species of conservation concern (C), and an index of relative abundance (A)

\begin{tabular}{|c|c|c|c|c|c|c|c|c|c|c|c|c|}
\hline \multirow{2}{*}{$\begin{array}{l}\text { Random term } \\
\text { Measure }\end{array}$} & \multicolumn{3}{|c|}{ Component } & \multicolumn{3}{|c|}{$\%$ of total for an observation } & \multicolumn{3}{|c|}{ Component after fitting vegetation cover } & \multicolumn{3}{|c|}{$\%$ explained by vegetation cover } \\
\hline & $\mathbf{R}$ & $\mathbf{C}$ & $\mathbf{A}$ & $\mathbf{R}$ & $\mathbf{C}$ & $\mathbf{A}$ & $\mathbf{R}$ & $\mathbf{C}$ & $\mathbf{A}$ & $\mathbf{R}$ & $\mathbf{C}$ & $\mathbf{A}$ \\
\hline Landscape & 29 & 0.5 & 0.8 & 44 & 38 & 47 & 5.0 & 0.22 & 0.38 & 83 & 56 & 77 \\
\hline Year & 3.8 & 0 & 0.02 & 4 & 0 & 1.3 & 1.7 & 0 & 0 & 55 & - & 100 \\
\hline Residual & 33 & 0.8 & 0.9 & 50 & 62 & 52 & 36 & 0.81 & 0.96 & & & \\
\hline
\end{tabular}


Table 2. Parameters and associated statistics for spatial and temporal relationships between bird biodiversity and log vegetation cover at the landscape scale. R: overall number of species, $C$ : the number of species of conservation concern, and A: an index of relative abundance.

\begin{tabular}{|c|c|c|c|c|c|c|c|c|c|}
\hline Parameter & \multicolumn{3}{|c|}{ Estimate } & \multicolumn{3}{|c|}{ s.e. } & \multicolumn{3}{|c|}{ p-value } \\
\hline Measure & $\mathbf{R}$ & $\mathbf{C}$ & $\mathbf{A}$ & $\mathbf{R}$ & $\mathbf{C}$ & $\mathbf{A}$ & $\mathbf{R}$ & $\mathbf{C}$ & $\mathbf{A}$ \\
\hline Constant & 40.2 & 3.12 & 1.4 & 1.0 & 0.16 & 0.2 & & & \\
\hline $\log \%$ vegetation cover (overall) & 4.5 & 0.46 & 0.57 & 0.96 & 0.16 & 0.2 & $<0.001$ & 10.0080 & .005 \\
\hline $\log \%$ vegetation cover (between landscapes) & 4.7 & 0.50 & 0.62 & 0.97 & 0.16 & 0.2 & $<0.001$ & 10.006 & 0.003 \\
\hline $\log \%$ vegetation cover (within landscapes) & -0.7 & -0.70 & -0.9 & 6.7 & 0.95 & 1.0 & 0.39 & 0.48 & 0.040 \\
\hline
\end{tabular}




\section{Figure legends}

Fig. 1. The nested study design showing sites within farms (circled) and farms within landscapes at two time points (2002 and 2010). The background in grey shows the spatial coverage of forest extent in 2002 and 2010. The numbers inside the circles correspond to the number of species of birds found on a landscape, on a farm or on a site.

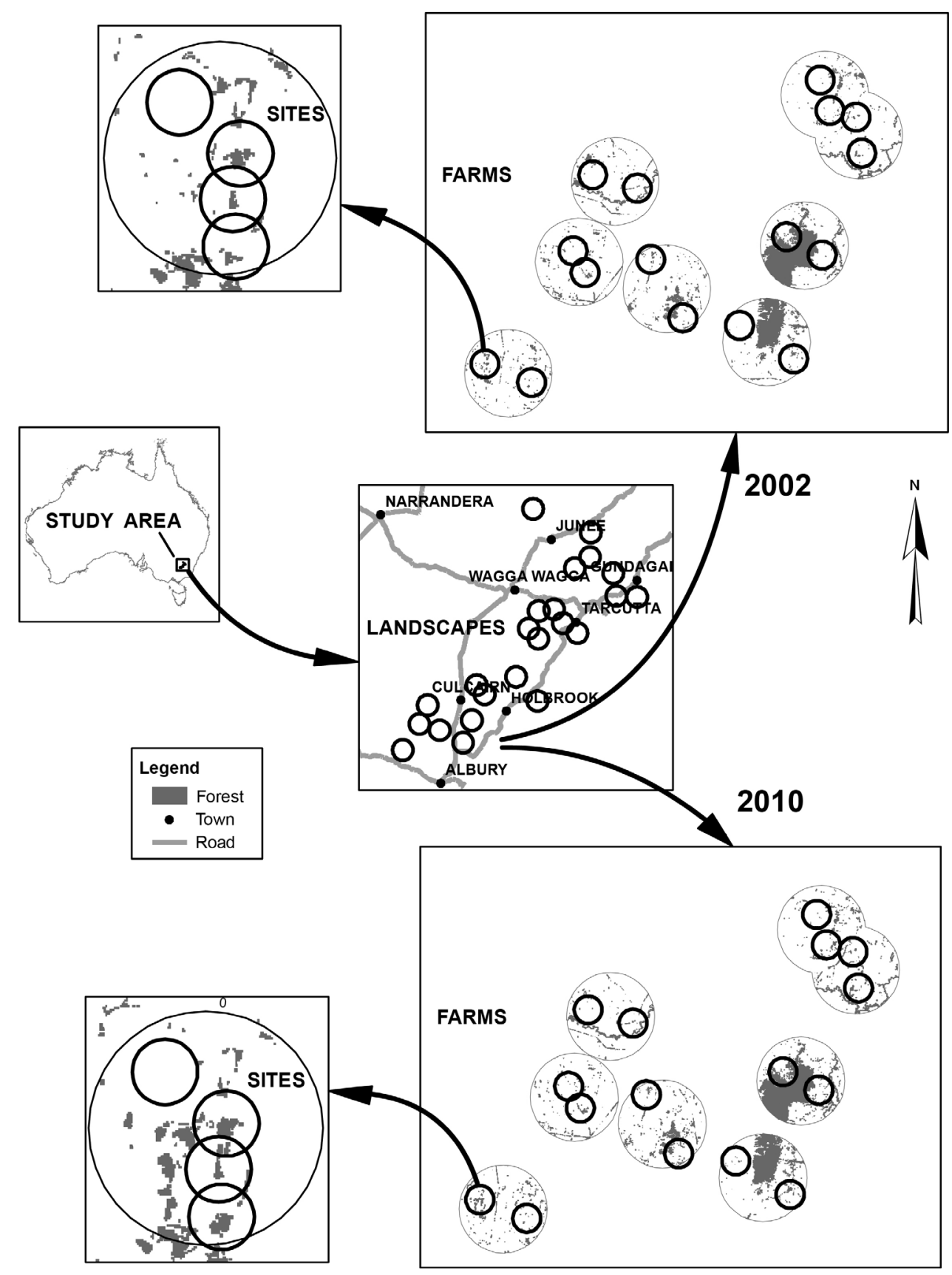


Fig. 2. (A) Relationships between mean bird species richness and vegetation cover for each landscape (denoted by the solid points). The between-landscapes regression is represented by the long solid line and the average within-landscape regression by the short line through each point. (B) Relationship between the predicted mean (and 95\% CI) bird species richness per landscape and \% native vegetation cover. (C) Relationship between the predicted mean number (and 95\% CI) of bird species of conservation concern per landscape and $\%$ native vegetation cover. (D) Relationship between the predicted abundance index per landscape (and $95 \% \mathrm{CI}$ ) and $\%$ native vegetation cover.
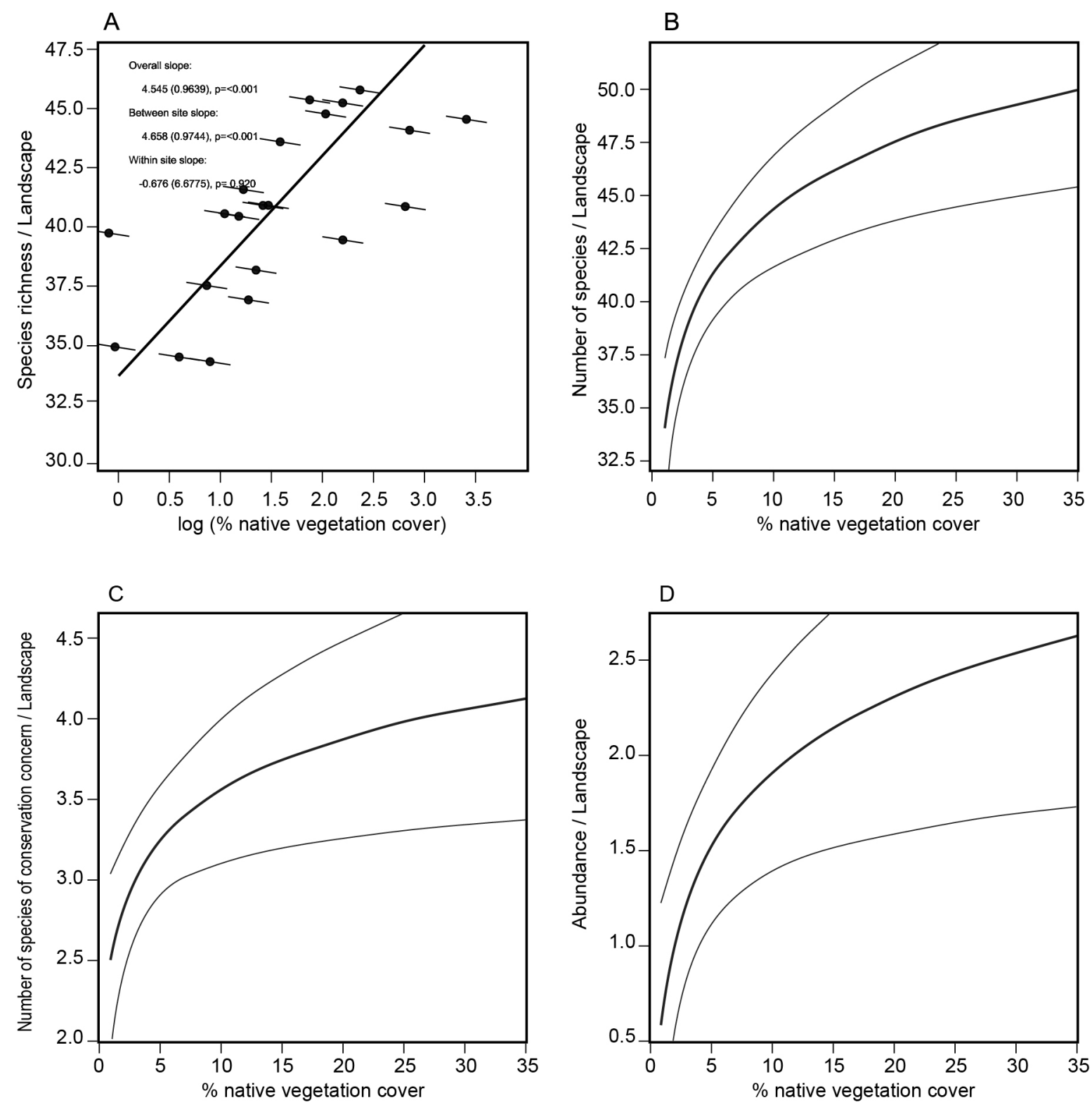
Fig. 3. (A) Relationships between mean bird species richness and vegetation cover for each farm (denoted by the solid points). The between-farms regression is represented by the long solid line and the average within-farm regression by the short line through each point. (B) Relationship between the predicted mean (and 95\% CI) bird species richness per farm and \% native vegetation cover. (C) Relationship between the predicted mean number (and 95\% CI) of bird species of conservation concern per farm and \% native vegetation cover. (D) Relationship between the predicted abundance index per farm (and 95\% CI) and \% native vegetation cover.
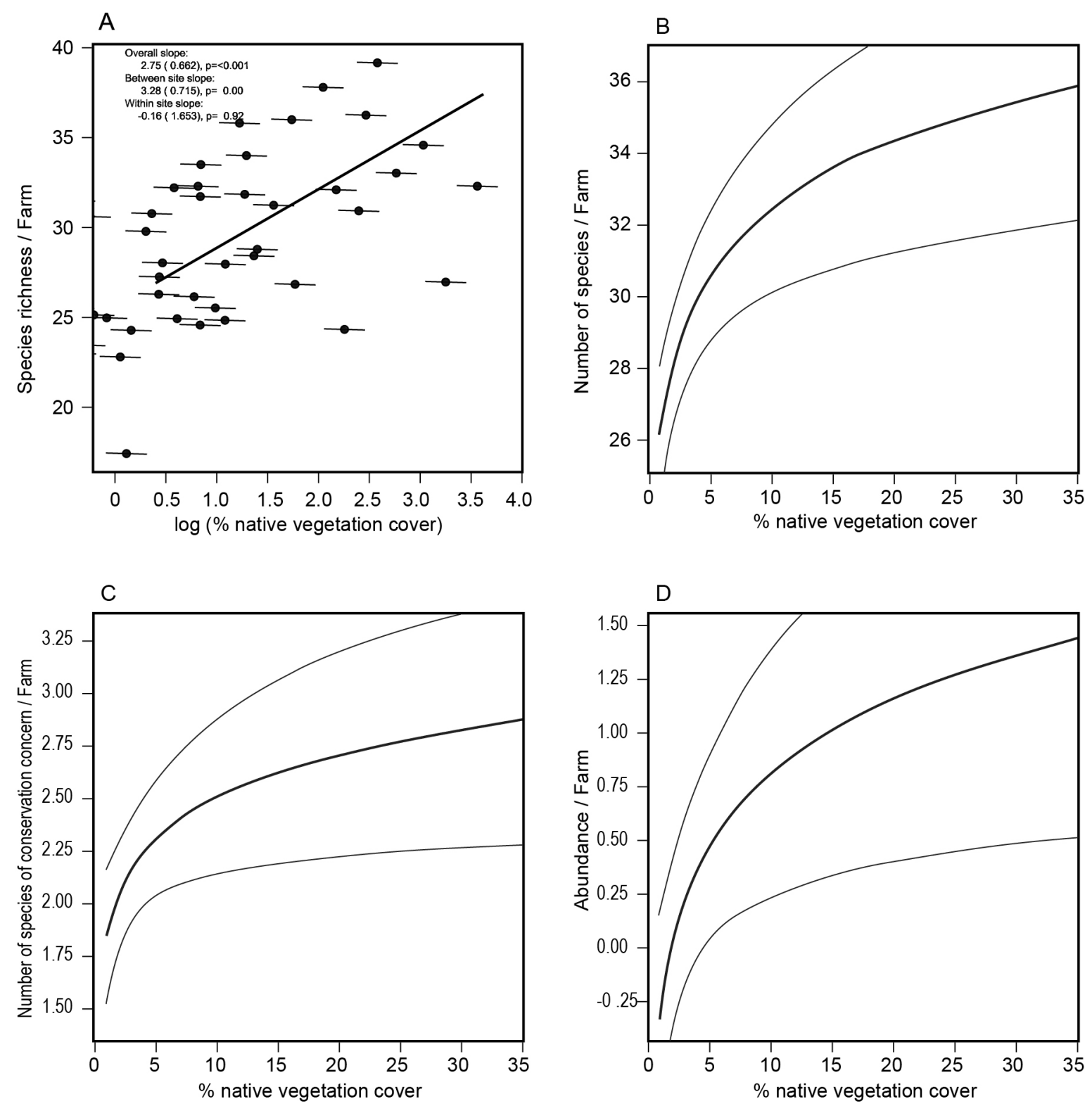
Fig. 4. (A) Relationships between mean bird species richness and \% vegetation cover for each site (denoted by the solid points). The between-sites regression is represented by the long solid line and the average within-sites regression by the short line through each point.

(B) Relationship between the predicted mean (and 95\% CI) bird species richness per site and $\%$ native vegetation cover. (C) Relationship between the predicted mean number (and 95\% CI) of bird species of conservation concern per site and \% native vegetation cover. (D) Relationship between the predicted abundance index per site (and 95\% CI) and \% native vegetation cover.
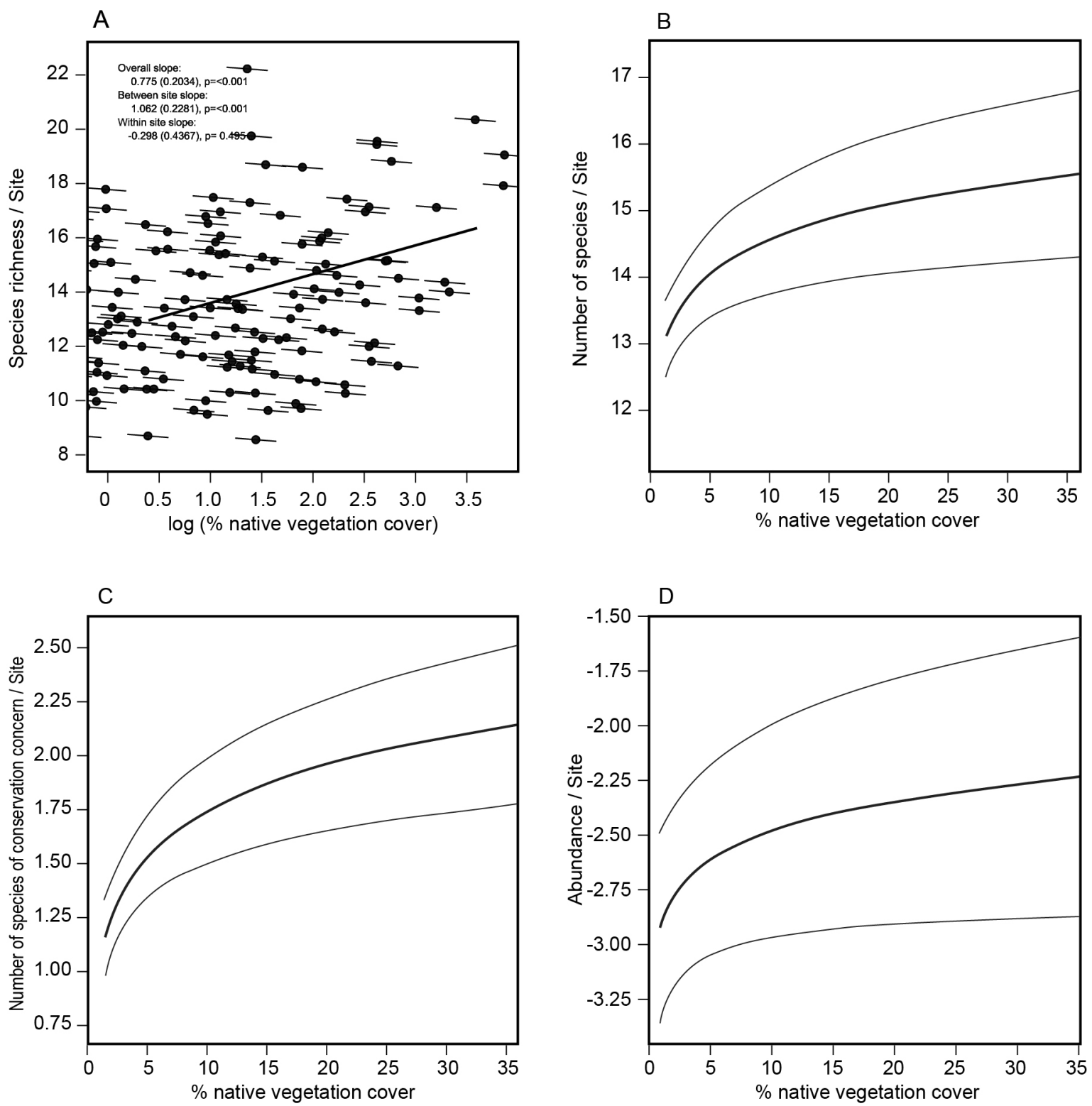